\title{
EFFECTIVENESS OF PROGRAMMED DEEP BREATHING EXERCISES ON REDUCING THE LEVEL OF FATIGUE DURING EXTERNAL RADIATION THERAPY
}

\author{
Rajita Devi1 ${ }^{1}$ Hiranya Kumar Saharia ${ }^{2}$
}

${ }^{1}$ Lecturer (Medical Surgical Nursing), Department of Oncology, Hayat Institute of Nursing Education, Hayat Hospital, Guwahati. ${ }^{2}$ Assistant Professor (Anaesthesiology and Critical Care), Department of Emergency Medicine, Gauhati Medical College and Hospital, Guwahati.

\section{ABSTRACT}

\section{CONTEXT}

Cancer related fatigue is the most common symptom described by cancer patients receiving radiation therapy.

\section{AIM}

To assess the effectiveness of programmed deep breathing exercises on reducing the level of fatigue during external radiation therapy in cancer patients in some selected hospitals of Guwahati, Assam.

\section{SETTINGS AND DESIGN}

Experimental, pretest- post-test control group designed to select 60 cancer patients in Dr. B. Barooah Cancer Institute and North East Cancer Hospital and Research Institute, Guwahati.

\section{MATERIALS AND METHODS}

Simple random sampling to select 30 patients in experimental and 30 in control group, the experimental group was given deep breathing exercises for 5 days and level of fatigue was assessed by Cancer Fatigue Scale for both the groups.

\section{STATISTICAL ANALYSIS USED}

SPSS Version 15. Frequency, percentage, mean, standard deviation, paired ' $t$ ' test, Chi-square test.

\section{RESULTS}

Results suggested that irrespective of age, sex, marital status, education, occupation, religion, diagnosis, stage of cancer, duration of radiation therapy, all cancer patients developed fatigue and significant difference was found between the control group and the experimental group after the implementation of deep breathing exercises in all the three subscales of radiation induced fatigue, physical $(p=0.03)$, affective $(p=0.01)$ and cognitive $(p=0.02)$. Age $(p=0.01)$, stage of cancer $(p=0.03)$ and duration of radiation therapy $(p=0.02)$ were significantly associated with the level of fatigue.

\section{CONCLUSION}

Deep breathing exercises are an effective intervention in reducing fatigue among cancer patients and can be effectively utilized by oncology nurses to improve quality of life.

\section{KEYWORDS}

Cancer, Fatigue, Radiation Induced Fatigue, Radiation Therapy, Cancer Fatigue Scale, Deep Breathing Exercises.

HOW TO CITE THIS ARTICLE: Devi R, Saharia HK. Effectiveness of programmed deep breathing exercises on reducing the level of fatigue during external radiation therapy in cancer patients. J. Evolution Med. Dent. Sci. 2016;5(38):2340-2344, DOI: $10.14260 /$ jemds/2016/543

\section{INTRODUCTION}

Non-communicable diseases including cancer are emerging as major public health problems in India. These diseases being lifestyle related have a long latent period and needs specialized infrastructure and human resources for management.

Financial or Other, Competing Interest: None.

Submission 13-03-2016, Peer Review 20-04-2016,

Acceptance 28-04-2016, Published 12-05-2016.

Corresponding Author:

Dr. Hiranya Kumar Saharia,

Assistant Professor,

Anaesthesiology and Critical Care,

Department of Emergency Medicine,

Gauhati Medical College and Hospital,

Guwahati.

E-mail: sahariahiranya@gmail.com

DOI: $10.14260 /$ jemds $/ 2016 / 543$
A high burden of preventable non-communicable diseases on India make it a movable competition for the resources allocation based on the cancer registry data; it is estimated that there is about 80000 new cancer cases and there is likely to be 3 times this load that is about 240,000 cases at any point in India.[1]

American Cancer Society reported that fatigue is the most common symptom described by patients with cancer, with reports of prevalence ranging from $60 \%$ to more than $90 \%$. Studies of side effects of cancer therapy have noted that $80 \%$ to $96 \%$ of patients receiving chemotherapy experienced fatigue. Reports concerning radiation treatment have also found fatigue to be present in $60-93 \%$ of patients.[2]

Regular exercise is an effective way to counteract the negative effectiveness of inactivity in chronic illness. Too much rest may result in loss of function, strength and range of motion in the person with a chronic illness. 
As a result, many health care providers are encouraging their patients to be as physically active as possible during cancer treatment.[3]

So, the investigator has undertaken this study in selected cancer hospitals of Guwahati, Assam, to assess the effectiveness of programmed deep breathing exercises in reducing the level of fatigue in patients receiving external radiation therapy and the investigator believes that this study will give evidence based practice to health professionals working in radiation oncology units of cancer hospitals to improve the quality of life of cancer patients.

\section{AIMS AND OBJECTIVES OF THE STUDY}

- To assess the level of fatigue in cancer patients during external radiation therapy in the experimental group and control group.

- To analyse the effectiveness of programmed deep breathing exercises on reducing level of fatigue in cancer patients during external radiation therapy.

- To determine the association between the level of fatigue with selected variables such as age, gender, marital status, religion, diagnosis, stage of cancer, mode of treatment, duration of radiation therapy, educational qualification and occupation.

\section{MATERIALS AND METHODS}

This was an evaluative study with pretest- post-test control group design conducted in 60 patients (30 samples in the experimental group and 30 in the control group) in radiation unit of Dr. B. Barooah Cancer Institute and North East Cancer Hospital and Research Institute, Guwahati, Assam, by using simple random sampling. All patients aged between 30 and 70 years who were diagnosed with cancer of head and neck region, breast and chest area and who have been receiving external radiation therapy for at least 5 days and are scheduled for another 5 days were included in the study. The exclusion criteria were: patients who are critically ill and who are getting radiation therapy along with chemotherapy.

The investigator used both structured (Section A) and standardized (Section B and C) tools for data collection. The tools were self-administered and the respondents were given proper instructions before they computed their responses.

\section{Section A}

This section consists of an interview schedule for collecting selected variables for research study. It includes 10 items to collect selected variables for the present study namely; age, gender, marital status, religion, diagnosis, stage of cancer, mode of treatment, duration of radiation therapy, educational qualification and occupation.

\section{Section B}

It consists of standardised Cancer Fatigue Scale (CFS) to assess radiation induced fatigue by. It is a self-administered questionnaire, three-dimensional, self-rating scale for assessment of fatigue in cancer patients. It covers three subjective dimensions (Physical, cognitive and affective) and has 15 items to measure the level of fatigue. CFS is a brief, valid and feasible scale for assessing the three dimensions of fatigue experienced by cancer patients. The CFS had good stability (Average test-retest reliability $r=0.69, p<0.001$ ) and good internal consistency (Cronbach's alpha coefficient for all 15 items $=0.88$.
Section C: It consists of techniques of deep breathing exercises to the experimental group that is administered 5 times in a day for 5 days. The deep breathing exercises used in the study were $4 \times 4$ technique, pursed lip breathing and diaphragmatic breathing.

After formal permission was obtained from concerned authorities of both the institutes, the main study was conducted in the radiation unit of both the hospitals from January 2013 to February 2014 by the investigator itself; 60 samples for the study were selected by simple random sampling and were randomly assigned into experimental group (30) and control group (30). Purpose of the study was explained and confidentiality of the responses was assured.

Informed written consent was taken from participants and pretest was taken by using the self-rating questionnaire from both experimental group and control group in Assamese version. Deep breathing exercises were administered to the experimental group 5 times in a day for 5 days for 15 minutes each and control group was administered standard care. Posttest was taken from both experimental group and control group at the end of 5 days.

\section{RESULTS}

Results were reported as mean \pm standard deviation. P value of $<0.05$ was considered statistically significant. Distribution of subjects according to selected variables in the control and experimental group.

\section{Age and Sex}

Majority of the patients in control group (60\%) and experimental group (55\%) were in the age group of 50-59 years, were males in both the control group (63.33\%) and experimental group (56.67\%) respectively.

\section{Marital Status}

As regards to marital status, majority of patients in both control group (80\%) and experimental group (90\%) were married.

\section{Religion}

Majority of the clients were Hindu in both in control (73.33\%) and experimental (80\%) groups.

\section{Diagnosis}

As regards to diagnosis of patients, majority of patients in the control group (46.67\%) and experimental group (40\%) were diagnosed with cancer of oesophagus, followed by cancer of tongue, $13.33 \%$ in the control group and $23.33 \%$ in the experimental group. The types of cancer that were found to be low incidence were cancer of alveolar ridge, cancer of hard palate, cancer of larynx, cancer of mandible, cancer of maxilla, cancer of parotid gland, cancer of thyroid and astrocytoma.

\section{Stage of Cancer}

In stage of cancer, majority of patients in both control group (60\%) and experimental group (56.67\%) had stage II cancer.

\section{Duration of Radiation Therapy}

Regarding the duration of radiation therapy, majority of the patients had 6-10 days of radiation therapy in both the control group (56.66\%) and experimental group (50\%) respectively. 


\section{Educational Qualification}

Majority of the patients in both control group (76.67\%) and experimental group (70\%) had primary level education.

\section{Occupation}

In occupation of the patients, majority of the clients in both the control group (40\%) and experimental group (50\%) were unemployed/home maker, followed by self-employed $30 \%$ in the control group and $20 \%$ in the experimental group.

Assessment of Level of Fatigue in Cancer Patients Receiving External Radiation Therapy

Majority of the patients had mild fatigue in both the control group (46.66\%) and experimental group (43.33\%). Patients reported to have similar levels of fatigue in both the control and experimental group and mostly patients were reported to have mild fatigue at the beginning of the external radiation therapy [Table 1].

In the post-test score majority of the patients in the control group had moderate level of fatigue (66.66\%), 30\% of the patients reported to have severe fatigue and only $3.33 \%$ of the patients had mild fatigue. Whereas, in the experimental group majority of the patients had mild fatigue $(66.66 \%)$, $26.66 \%$ had moderate fatigue and only $6.66 \%$ had severe fatigue. At the beginning of radiation therapy majority of the patients had mild fatigue, but as the duration of radiation therapy increased the level of fatigue also increased significantly [Table 2].

Effectiveness of Programmed Deep Breathing Exercises in Reducing the Level of Fatigue in Cancer Patients Receiving External Radiation Therapy

Statistically, it reveals that there was significant reduction in physical subscale $(p=0.03)$, affective subscale $(p=0.01)$ and cognitive subscale $(p=0.02)$ of fatigue after the intervention of deep breathing exercises [Table 3].

So it can be interpreted from the study findings that deep breathing exercises were effective intervention in reducing the level of fatigue in cancer patients receiving external radiation therapy and can be incorporated in oncology practice to improve the quality of life of cancer patients.

\section{Association between the Level of Fatigue and Selected Variables \\ In analysing data on association between level of fatigue and selected variables such as gender, marital status, religion, diagnosis, mode of treatment, educational qualification and occupation showed no statistically significant association but there was significant association between level of fatigue and age (Chi square=15.883, p=0.01), stage of cancer (chi square $=12.963, \mathrm{p}=0.03$ ) and duration of radiation therapy (chi square $=28.667, \mathrm{p}=0.02$ ) [Table 4].}

\begin{tabular}{|c|c|c|c|c|c|}
\hline Pretest Level of Fatigue & Score Range & \multicolumn{2}{|c|}{ Control } & \multicolumn{2}{c|}{ Experimental } \\
\hline & & Frequency & $\%$ & Frequency & \% \\
\hline Mild & $15-35$ & 14 & 46.66 & 11 & 43.33 \\
\hline Moderate & $36-49$ & 10 & 33.33 & 13 & 36.66 \\
\hline Severe & $50-75$ & 20 & 6 & 20 \\
\hline \multicolumn{2}{|r|}{ Table 1: Assessment of Pre-Test Score of Level of Fatigue in the Control Group and Experimental Group, $\mathbf{n = 6 0}$} \\
\hline
\end{tabular}

\begin{tabular}{|c|c|c|c|c|c|}
\hline Post-test Level of Fatigue & Score Range & \multicolumn{2}{c|}{ Control } & \multicolumn{2}{c|}{ Experimental } \\
\hline & & Frequency & $\%$ & Frequency & $\%$ \\
\hline Mild & $15-35$ & 1 & 3.33 & 20 & 66.66 \\
\hline Moderate & $36-49$ & 20 & 66.66 & 8 & 26.66 \\
\hline Severe & $50-75$ & 9 & 30.00 & 2 & 6.66 \\
\hline
\end{tabular}

\begin{tabular}{|c|c|c|c|c|c|c|c|}
\hline \multirow{2}{*}{ Level of Fatigue } & \multicolumn{2}{|c|}{ Control Group } & \multicolumn{2}{|c|}{ Experimental Group } & t value & df & p value \\
\hline & Mean & SD & Mean & SD & \multirow{4}{*}{1.19} & \multirow{4}{*}{58} & \multirow{4}{*}{$0.03^{\mathrm{S}}$} \\
\hline \multicolumn{5}{|l|}{ Physical Fatigue } & & & \\
\hline Pre test & 22.90 & 4.25 & 21.63 & 4.00 & & & \\
\hline Post test & 24.57 & 3.77 & 18.37 & 3.03 & & & \\
\hline Affective Fatigue & & & & & \multirow[b]{3}{*}{1.42} & \multirow[b]{3}{*}{58} & \multirow[b]{3}{*}{$0.01^{\mathrm{s}}$} \\
\hline Pre test & 9.63 & 2.48 & 10.13 & 1.78 & & & \\
\hline Post test & 10.40 & 2.54 & 8.87 & 1.78 & & & \\
\hline \multicolumn{5}{|l|}{ Cognitive Fatigue } & \multirow[b]{3}{*}{2.44} & \multirow[b]{3}{*}{58} & \multirow[b]{3}{*}{$0.02^{\mathrm{s}}$} \\
\hline Pre test & 10.27 & 2.59 & 11.33 & 3.19 & & & \\
\hline Post test & 11.00 & 2.44 & 9.50 & 2.33 & & & \\
\hline \multicolumn{8}{|c|}{$\begin{array}{c}\text { Table 3: Effectiveness of Deep Breathing Exercises on Physical Subscale of Level } \\
\text { of Fatigue in Control Group and Experimental Group, } n=60\end{array}$} \\
\hline
\end{tabular}

Significant level $<0.05$, S-Significance, NS-Non significance. 


\begin{tabular}{|c|c|c|c|c|c|c|}
\hline \multirow{2}{*}{ Age in Years } & \multicolumn{3}{|c|}{ Pre Test Level of Fatigue } & \multirow{2}{*}{ Chi Square } & \multirow{2}{*}{ df } & \multirow{2}{*}{$p$ value } \\
\hline & Mild & Moderate & Severe & & & \\
\hline $30-39$ & 0 & 6 & 1 & \multirow{5}{*}{15.833} & \multirow{5}{*}{6} & \multirow{5}{*}{$0.015^{\mathrm{s}}$} \\
\hline $40-49$ & 0 & 7 & 1 & & & \\
\hline $50-59$ & 5 & 1 & 2 & & & \\
\hline $60-69$ & 1 & 4 & 2 & & & \\
\hline Total & 6 & 18 & 6 & & & \\
\hline \multirow{2}{*}{ Stage of Cancer } & \multicolumn{3}{|c|}{ Pre Test Level of Fatigue } & \multirow{2}{*}{ Chi Square } & \multirow{2}{*}{ df } & \multirow{2}{*}{ p value } \\
\hline & Mild & Moderate & Severe & & & \\
\hline Stage I & 1 & 1 & 0 & \multirow{5}{*}{12.963} & \multirow{5}{*}{6} & \multirow{5}{*}{$0.03^{\mathrm{s}}$} \\
\hline Stage II & 5 & 6 & 2 & & & \\
\hline Stage III & 0 & 7 & 2 & & & \\
\hline Stage IV & 0 & 0 & 6 & & & \\
\hline Total & 6 & 14 & 10 & & & \\
\hline \multirow{2}{*}{ Duration of RT } & \multicolumn{3}{|c|}{ Pre Test Level of Fatigue } & \multirow{2}{*}{ Chi Square } & \multirow{2}{*}{ df } & \multirow{2}{*}{ p value } \\
\hline & Mild & Moderate & Severe & & & \\
\hline 6-10 days & 5 & 5 & 5 & \multirow{5}{*}{28.667} & \multirow{5}{*}{26} & \multirow{5}{*}{$0.02^{\mathrm{s}}$} \\
\hline 11-15 days & 0 & 4 & 2 & & & \\
\hline 16-20 days & 1 & 3 & 1 & & & \\
\hline$>21$ days & 0 & 2 & 2 & & & \\
\hline Total & 6 & 14 & 10 & & & \\
\hline
\end{tabular}

Significant level $<0.05$, S-Significance, NS-Non Significance.

\section{DISCUSSION}

Cancer related fatigue is a distressing, persistent, subjective sense of tiredness or exhaustion that occurs in $70-100 \%$ of cancer patients receiving radiotherapy or chemotherapy. Its severity increases to a very high extent. It affects the quality of life, interferes with ability to work, relationship with others, physical and emotional well-being. Now-a-days there has been growing interest in managing these symptoms with nonpharmacological treatments.

The present study aims to assess the effectiveness of deep breathing exercises in reducing level of fatigue in cancer patients receiving external radiation therapy.

The study reflected that highest number of the patients were males (60\%), married (85\%), belonged to Hindu religion (76.6\%), were diagnosed with cancer of oesophagus $(43.3 \%)$ had stage II cancer (58.33\%) and had undergone radiation therapy only as the mode of treatment (68.33\%).

It has been observed that deep breathing exercises reduced level of fatigue significantly in cancer patients receiving external radiation therapy in all the three subscales of radiation induced fatigue, physical subscale $(p=0.03)$, affective subscale $(p=0.01)$ and cognitive subscale $(p=0.02)$. It is probably due to the reason that deep breathing exercises expand the alveoli, allows for more oxygenation of tissues and also aids in relaxation of body and mind. Similar findings were reported by Mock Victoria and Pickett Mary.[4] that fatigue levels were approximately 40-50\% lower in exercising subjects.

The present study revealed a significant association between level of fatigue and age of the patient $(p=0.015)$, stage of cancer ( $p=0.03)$ and duration of radiation therapy $(p=0.02)$. There was no significant association found between gender, marital status, religion, diagnosis, mode of treatment, educational qualification and occupation.

Association between age of the patient and level of fatigue may be attributed to cellular breakdown in aging adults, emotional instability and lack of support system in family as higher levels of fatigue was found in the age group of 60-69 years.

The findings corroborate with the findings of many scholars who revealed that selected factors such as age, duration of radiation therapy have significant association with level of fatigue. A study conducted by Goedendorp MM et al[5] also revealed that fatigue has significant association with age $(p=0.014)$, stage of cancer $(p=0.045)$, lower physical activity $(\mathrm{p}=0.013)$

The present study reported a significant association between duration of radiation therapy ( $p=0.02)$ with level of fatigue. This may be attributed to physical and psychological exhaustion caused by cancer treatment and distressing side effects. Similar findings were reported by Albuquerque Kevin et al[6] in a prospective longitudinal study to examine the effect of radiation therapy on fatigue and it were reported that higher duration of radiation therapy was significantly associated with level of fatigue $(\mathrm{p}=0.02)$.

This study is also supported by finding of Mulrooney DA and et al[7] that patients with a history of higher duration of radiation therapy were more likely to be fatigued (odds ratio $1.7,95 \%$ confidence interval 1.3-2.3).

The present study reported significant association of stage of cancer $(p=0.03)$ with the level of fatigue. Advanced stage of cancer was associated with higher levels of fatigue, probably due to advancing disease, distressing side effects of cancer treatment as well as the disease itself and unpredictable future events.

This finding is supported by studies conducted by Goedendorp MM et al[5], Singer S et al[8], Kurz K et al[9] where they reported that increasing higher stage of cancer is associated with increased inflammatory biomarkers that in turn produces more fatigue.

Oncologist and oncology nurses are in best position to help out cancer patients to prevent distress. Recently, the uses of cognitive behavioural coping strategies are recommended as an adjuvant to cancer treatment. 


\section{CONCLUSION}

It has been observed from the study findings that level of fatigue of cancer patients receiving external radiation therapy is independent of gender, marital status, education, occupation, diagnosis of patients, etc. So, all patients need to be assessed for fatigue severity and managed accordingly. Fatigue is the most distressing side effect of radiation therapy and use of medications has a little impact on managing fatigue. Moreover, non-pharmacological methods for management of problems are preferred over pharmacological methods. Deep breathing exercises being one of the non-invasive and nonpharmacological techniques can be of great help and it should be incorporated in radiation oncology units of cancer hospitals to help cancer patients overcome this distressing feeling and improve their quality of life.

\section{REFERENCES}

1. Ahmedin Jemus, Siegel Rebecca, Ward Elizabeth. Cancer Statistics 2007. A Can Jour for Clinicians 2007;57(1):43-66.

2. American cancer society. Physical activity and the cancer patient 2007. Available from http: //www.cancer.org.com.

3. Aghili M. Effectiveness of programmed exercises on level of fatigue in cancer patients during external radiation therapy. European jour of onco nurs 2007;11:179-182.

4. Victoria mock and mary pickett. Fatigue and quality of life outcomes of exercise during cancer treatment 1999. Clin J Oncol Nurs 2006;52:97-102. available from: http // www.medicinenet.com/aerobic_exercise/.
5. Goedendorp MM, Gielissen MF, Verhagen CA, et al. Severe fatigue and related factors in cancer patients before the initiation of treatment. Brtsh Jour of Cancer 2010;99:140814. Available at: http://www.ncbi.nlm.nih.gov/pmc/articles/PMC2579682/.

6. Albuquerque K, Dina T, Philip L. Impact of partial versus whole breast radiation therapy on fatigue, perceived stress, quality of life and natural killer cell activity in women with breast cancer. Bio Med Central Cancer 2003;12:251.

7. Mulrooney DA, Ness KK, Neglia JP, et al. Fatigue and sleep disturbance in adult survivors of childhood cancer after radiation therapy. SLEEP 2008;31(2):271-81. Available on: http://www.ncbi.nlm.nih.gov/pmc/articles/PMC2225565/.

8. Singer S, Kuhnt S, Zwerenz R. Age- and sex-standardised prevalence rates of fatigue in a large hospital-based sample of cancer patients. British Journal of Cancer 2011;105(3):445-51. Available at: http://www.ncbi.nlm.nih.gov/pmc/articles/PMC3172908/.

9. Kurz K, Fiegl M, Bernhard H. Fatigue in patients with lung cancer is related with accelerated tryptophan breakdown. Peer Reviewed Open access Journal 2004;7:66-8. available from:http://www.ncbi.nlm.nih.gov/pmc/articles/PMC33539 $90 /$. 